\title{
An Examination of the Influences on Active Commuting among a Sample of Parents
}

\author{
Shannon Larson, Ronald E. Green, Dangaia Sims, Melissa Bopp ${ }^{*}$, Joanna Colgan \\ Department of Kinesiology, Pennsylvania State University, University Park, PA, USA \\ *Corresponding author:mjb73@psu.edu
}

\begin{abstract}
Active commuting (AC; walking and biking to work) is associated with significant health benefits. AC rates remain low in the United States, particularly among parents; accordingly, it is important to understand factors associated with $\mathrm{AC}$ for potential intervention development. The purpose of this study was to examine the multi-level influences of AC participation in parents who are currently regular active commuters. At the individual level, the benefits of exercise, enjoyment of AC, and the use of child-friendly bicycle accessories facilitated AC; however, time and effort were also shown to impede AC. Positive interpersonal influences included spousal support and scheduling, an AC supportive work environment, and interest from the children, whereas negative influences included childcare and time for travel to school. Environmental factors (i.e., weather, terrain, distance, and infrastructure) appeared to both support and inhibit AC. These findings from successful active commuters may be used to inform future $\mathrm{AC}$ interventions.
\end{abstract}

Keywords: active travel, adults, parents, social ecological

Cite This Article: Shannon Larson, Ronald E. Green, Dangaia Sims, Melissa Bopp, and Joanna Colgan, "An Examination of the Influences on Active Commuting among a Sample of Parents." Journal of Physical Activity Research, vol. 2, no. 2 (2017): 124-129. doi: 10.12691/jpar-2-2-10.

\section{Introduction}

Only 1 in 5 adults meet the physical activity (PA) guidelines recommended by the United States Department of Health and Human Services, which suggest that adults ages 18 to 64 reach 150 minutes of moderate-intensity aerobic activity, 75 minutes of vigorous-intensity aerobic activity, or an equivalent combination of the two, every week $[1,2]$. This is of significant public health concern as only $20 \%$ of adults are receiving the benefits that regular PA provides. Regular PA results in enhanced physical and mental function, better quality of life, and disease prevention, including heart disease, diabetes, arthritis, depression and some types of cancer [1].

Rates of PA participation typically decline with age and are lower among women compared with men and among adults compared with children. There have been significant findings relating age-specific life transitions to changes in PA levels $[3,4,5]$. When focusing on PA changes in women, it has been observed that PA levels decreased significantly after marriage and childbirth, and as women aged and their health declined $[6,7,8,9]$.

Active commuting (AC), which encompasses walking and biking to work, is an effective strategy to integrate PA into a daily routine and help meet current PA guidelines. Regular AC participation is associated with many of the same benefits of PA participation, including a decreased risk of chronic disease $[10,11,12]$, improved mental health [13], and fitness outcomes [14]. Despite these known benefits, rates of $\mathrm{AC}$ in the United States are low, with less than $5 \%$ of the population walking or biking to work [15]. Some groups of the population have lower rates of $\mathrm{AC}$ than national averages, notably parents and women $[16,17,18]$, with Whitfield et al. [19] reporting in a review of multiple data collection systems that women tend to report less AC to work than men.

Within a social ecological framework [20], there are many different factors that can influence AC participation. Various studies have shown that there are different individual, social, and environmental factors that have impact AC participation. Demographics, psychological factors and beliefs associated with AC have been shown to relate to $\mathrm{AC}$ at the individual level $[21,23,24]$. At an interpersonal or social level co-worker and spousal support for AC and social norms for AC have been noted influences on participation $[17,25,26]$. There is abundant research documenting environmental factors that influence AC participation, including having a shorter commute, living in a neighborhood with connected streets, and worksite supports (e.g. schedule, showers, locker rooms, bike parking) $[17,27,28,29,30]$. It is important to acknowledge the factors that prevent or motivate adults to $\mathrm{AC}$ to further intervene on this behavior in the future.

Shifting demographics in the last 50 years have led to an increase in the number of men and women who are working parents. Currently in the United States, 6 in 10 families have both parents employed outside the home. Parents are often tasked with juggling their time demands between the workplace and home and face time-related challenges for engaging in self-care behaviors such as PA [31]. Active commuting could provide an avenue for engaging in regular PA while traveling to work, saving 
time. Despite the low rates of AC in general, and specifically among parents, there are individuals who are successfully engaging in this behavior. Identifying the strategies employed by parents who are able to be regular active commuters will allow us to develop effective interventions targeting adults. Therein, the purpose of this study was to qualitatively examine the individual, interpersonal and environmental factors that influenced AC participation in a sample of parents who were regular active commuters.

\section{Methods}

This was a cross-sectional, qualitative study conducted September 2013 to December 2014. This study was approved by the Institutional Review Board at Pennsylvania State University.

\subsection{Participants \& Recruitment}

Participants were recruited through flyers and e-mails at childcare facilities, local schools and the local bicycle coalition. Individuals needed to be parents of a child 12 years of age or younger and report active commuting to work one or more times a week to be eligible for the study. A total of 19 participants volunteered for the study, which was the point of data saturation. All were screened, eligible and participated. Once the screening process was completed, an interview was scheduled where the participant signed an informed consent form and filled out a basic demographic form.

\subsection{Procedure}

Table 1. Interview questions

Could you describe your typical active commute?

Could you tell me about some of the things that influence your choice of travel to or from work when you are traveling without your child?

How did you travel to work before you had children?

If they ever travel with their child:

What are some things that influence your travel choices when you travel with your child?

Thinking about all of the things you just mentioned, what would you consider to be the biggest barrier or challenge to actively traveling to work? Why?

What is the main incentive or motivating factor for why you would choose to actively travel? Why?

For parents of older children:

Has your choice of travel changed since after your child started attending school? Please describe.

How do some of the things you have described relate

to other aspects in your family life?

What kinds of things would you like to see in place to help you continue to travel actively to work?

All interviews were conducted in-person at the participant's location of choice (e.g., office) or on the phone. After providing consent, the participant was asked to complete a demographic questionnaire asking about themselves (age, sex, race/ethnicity, education) their children (how many, ages, number of extracurricular activities they participate in) and their health (height, weight, how often they exercise each week). The interview was conducted by a research assistant and followed a scripted guide that focused on the participant's typical AC patterns as well as the barriers and motivating factors that influence their choice to AC. Interview questions are noted in Table 1. The interview lasted approximately 15 minutes and participants were provided with a small incentive (\$10 gift card) for their participation.

\subsection{Theory}

The interview guide was grounded in the social ecological model, examining the influences on AC at individual, interpersonal, and environmental levels. This multi-level model allowed for a more comprehensive analysis to examine a wide range of possible influences on $\mathrm{AC}$ in this exploratory study.

\subsection{Data Analysis}

The interview was recorded and later transcribed verbatim. A coding guide was developed to reflect the social ecological framework and was used by two independent coders for each transcript, using standard qualitative methods for triangulation and coming to consensus. Each interview transcription was entered into the NVIVO software (QSR International, Melbourne, Australia) to be coded. The coding reports summarized the individual, interpersonal and environmental factors influencing AC.

\section{Results}

The demographics of the sample are found in Table 2. The participants were primarily male $(n=13)$, Caucasian $(\mathrm{n}=19)$, had a normal BMI 23.836 $\pm 3.34(\mathrm{n}=14)$, and selfreported that they were very healthy $(n=11)$. Additionally, most participants were middle aged $(40.4 \pm 4.45$ years $)$ and all had at least one child under the age of $12(n=19)$.

Table 2. Demographics of the Sample $(n=19)$

\begin{tabular}{|l|c|c|}
\hline Characteristic & Mean (SD) & $\mathrm{N}(\%)$ \\
\hline Gender, \% male & & $13(68)$ \\
\hline Race, \% Caucasian & & $19(100)$ \\
\hline Age & $40.4(4.45)$ & \\
\hline Number of Children & & \\
1 & & $2(11)$ \\
2 & & $12(62)$ \\
3 & & $3(16)$ \\
$4+$ & & $2(11)$ \\
\hline BMI & & \\
Normal $\left(19-24.9 \mathrm{~kg} / \mathrm{m}^{\wedge} 2\right)$ & & $2(11)$ \\
Overweight $\left(25-29.9 \mathrm{~kg} / \mathrm{m}^{\wedge} 2\right)$ & $2(11)$ \\
Obese (greater than $\left.30 \mathrm{~kg} / \mathrm{m}^{\wedge} 2\right)$ & & \\
\hline Self-Reported Health Status & & $3(17)$ \\
Excellent & & $11(61)$ \\
Very Good & & $4(22)$ \\
Good & & \\
\hline
\end{tabular}

\subsection{Travel Habits}

All participants were screened to be active commuters, including those who walked, biked or engaged in both forms of active travel. Parents reported living less than a mile $(n=4), 1-2$ miles $(n=5)$ and greater than 2 miles $(n=10)$ from their workplace. We examined how having children has changed how they travel to work; many $(n=10)$ noted that having children didn't change their commuting 
behavior. A few noted that they increased their AC, with one parent noting that they "wanted to keep the value of biking in [her] life." Three parents noted that it was more difficult to engage in AC after having children. Parents also noted that their children walked $(n=7)$ or biked $(n=6)$ to school, with the rest traveling via car or bus. For parents who traveled with their children (to childcare) $(n=9)$, the use of strollers $(n=4)$, bike trailers $(n=4)$, and bike tag-alongs $(n=1)$ were noted.

\subsection{Individual Level Factors}

The most cited individual level influence was that $\mathrm{AC}$ helped fit exercise into one's daily routine $(n=17)$. Other common themes included time constraints $(n=7)$, and enjoyment of $\mathrm{AC}(\mathrm{n}=3)$.

The use of additional accessories, especially for young children, was a recurring theme throughout the interviews. Items such as bike trailers and strollers were mentioned as both facilitators and inhibitors of $\mathrm{AC}$ for the participants who chose to bike to work. One participant explained that these accessories made it harder to AC, "It's easier to walk, its more flexible. You've got to do something with the bike and my even my daughter who is used to trailers, when you get there what are you supposed to do with the trailers?" Another participant discussed how using his tagalong was both rewarding and a challenge when $\mathrm{AC}$ with his daughter because "she had to start taking the bus. It was kind of a special thing that I would take her and then I would have to haul the tag-along all over creation. It was just kind of a pain, but it was worth it because I wanted to keep the value of biking in her life." The use of these accessories was cited as facilitators $(n=6)$ and as barriers $(n=7)$ throughout the interviews. Illustrative quotes for individual level influences are found in Table 3.

Table 3. Illustrative quotes for individual influences on active commuting

\begin{tabular}{|c|c|}
\hline Theme & uote \\
\hline $\begin{array}{lr}\text { Individual } & \text { level } \\
\text { Influence } & - \\
\text { Exercise } & \\
\text { (facilitator) } & \end{array}$ & $\begin{array}{l}\text { "The other big one is that biking to work becomes } \\
\text { my outlet for exercise. I don't go to a gym, I don't } \\
\text { see myself dedicating time in the evenings or } \\
\text { mornings to exercise at home. So that's my } \\
\text { exercise." - Male, } 40\end{array}$ \\
\hline $\begin{array}{lr}\text { Individual } & \text { level } \\
\text { Influence } & - \\
\text { Enjoyment } & \\
\text { (facilitator) } & \end{array}$ & $\begin{array}{l}\text { "It is the community that helps me walk. I often } \\
\text { will stop and get coffee on the way and it is not } \\
\text { uncommon to run into people and talk to them. So, I } \\
\text { do enjoy the community that we live in and that } \\
\text { aspect of walking" - Male, } 31 \\
\text { "The main thing in general is that I really mentally } \\
\text { enjoy riding my bike to work. I relax a lot and think } \\
\text { about the work that I am going to do that day. That } \\
\text { lets me sort of shift gears from being home to being } \\
\text { at work." - Male, } 39\end{array}$ \\
\hline $\begin{array}{l}\text { Individual level } \\
\text { influence - time } \\
\text { (barrier) }\end{array}$ & $\begin{array}{l}\text { "The biggest barrier was probably time and effort. } \\
\text { You know sometimes I would feel lazy or be tired } \\
\text { or have a cold. Sometimes you really got to push } \\
\text { through." - Male, } 39\end{array}$ \\
\hline $\begin{array}{l}\text { Use } \\
\text { accessories } \\
\text { (facilitator) }\end{array}$ & $\begin{array}{l}\text { "We try to avoid driving every day possible. So on } \\
\text { a day where we successfully do that, one of us will } \\
\text { carry the baby in a baby carrier, and the other one } \\
\text { will carry our four year old in the trailer behind the } \\
\text { bike." - Female } 36\end{array}$ \\
\hline $\begin{array}{l}\text { Use } \\
\text { accessories } \\
\text { (barrier) }\end{array}$ & $\begin{array}{l}\text { "[Active commuting] is a lot easier now that they're } \\
\text { older for sure. We don't have to get the stroller out } \\
\text { and get everything that covers kids and the } \\
\text { backpacks and the bike trailer. They can ride their } \\
\text { own bikes, they're more independent." - Female, } \\
42\end{array}$ \\
\hline
\end{tabular}

\subsection{Interpersonal Level Factors}

There was less of a consensus on interpersonal factors that impact $\mathrm{AC}$, however a few themes were prevalent throughout the study that can be found in Table 4 with illustrative quotations. The main theme that kept appearing throughout the interviews was that the ability to AC was largely determined by being able to schedule with their spouse, being cited in $94 \%$ of the interviews $(n=18)$. One participant explained, "I would say [living close to my work] is the biggest factor. And the fact that my husband works from home... so if we need to go get the kids if they're sick at school or whatever, he's able to do those things." Additionally, 47\% (n=9) of participants said that support from their spouse also encouraged them to AC more.

Many parents $(n=10)$ noted how AC helped contribute to the health of the family. Parents noted that, "it helps us to reinforce to the kids to be physically active and that's important too," and that "biking to work is simply an extension of living a healthy lifestyle." Other family benefits included economic savings $(n=6)$ and environmental friendliness $(n=3)$.

The themes most commonly cited as barriers were: childcare $(n=4)$, scheduling with spouse $(n=5)$, and getting kids to school $(n=3)$. The themes cited most as facilitators were: spousal support $(n=9)$, scheduling with spouse $(n=14)$ and support from the work environment $(n=4)$.

Table 4. Illustrative quotes for interpersonal influences on active commuting

\begin{tabular}{|c|c|}
\hline Theme & Quote \\
\hline $\begin{array}{l}\text { Child } \\
\text { (barrier) }\end{array}$ & $\begin{array}{l}\text { "Without my child, often child care will influence my } \\
\text { choices. If I have somebody coming to watch them } \\
\text { sometimes I do not have the extra time in my day to } \\
\text { take the few extra minutes to ride my bike to work." } \\
\text { - Female, } 34\end{array}$ \\
\hline $\begin{array}{l}\text { Disinterest from } \\
\text { Children } \\
\text { (barrier) }\end{array}$ & $\begin{array}{l}\text { "... sometimes they whine about walking. They } \\
\text { prefer to sit in the seat of a car than walk." - Male, } \\
40\end{array}$ \\
\hline $\begin{array}{l}\text { Children } \\
\text { Traveling to } \\
\text { School (barrier) }\end{array}$ & $\begin{array}{l}\text { "[One thing that influences when I actively commute } \\
\text { with my children is] how much time we have to get } \\
\text { them to school before school starts." - Female, } 42\end{array}$ \\
\hline $\begin{array}{l}\text { Spousal } \\
\text { Support } \\
\text { (facilitator) }\end{array}$ & $\begin{array}{l}\text { "My spouse is pretty willing to indulge my aversion } \\
\text { to driving so he's been great, makes it easier." - } \\
\text { Female, } 36\end{array}$ \\
\hline $\begin{array}{l}\text { Work } \\
\text { Environment } \\
\text { (facilitator) }\end{array}$ & $\begin{array}{l}\text { "I would come back and get her and take her home } \\
\text { and again that required some work place flexibility. } \\
\text { So yeah a supportive work environment just having } \\
\text { employee you know empowering work environment } \\
\text { certainly enables people to make these sorts of } \\
\text { choices" - Male, } 39\end{array}$ \\
\hline $\begin{array}{l}\text { Scheduling with } \\
\text { Spouse } \\
\text { (facilitator) }\end{array}$ & $\begin{array}{l}\text { "We only have one car so the biking to work gives } \\
\text { me more flexibility. So my wife works as well so } \\
\text { we're not trying to compete for the car" - Male, } 40\end{array}$ \\
\hline $\begin{array}{l}\text { Interest from } \\
\text { children } \\
\text { (facilitator) }\end{array}$ & $\begin{array}{l}\text { "So right now it is easy because they want to do it. } \\
\text { We don't need to convince to do it so we're just } \\
\text { letting it happen. I feel like we would like it as a } \\
\text { family, just for fun not like anything big. All four of } \\
\text { us have bikes. They see me biking every day, and } \\
\text { they like riding bikes. So we haven't even had to say } \\
\text { anything. They just do it." - Male, } 43\end{array}$ \\
\hline
\end{tabular}

\subsection{Environmental Factors}

Participants cited different environmental factors that influenced their choice to $\mathrm{AC}$, which can be found in Table 5 with illustrative quotations. There were four main themes that emerged: logistics, infrastructure, weather, 
and distance/terrain. The different environmental factors were frequently cited as either being barriers or as facilitators of AC. Specifically, each of the themes were mentioned as a barrier as follows: logistics $(n=6)$, infrastructure $(n=12)$, weather $(n=17)$ and terrain/distance $(n=6)$. Each theme was also mentioned as a facilitator as follows: logistics of weather $(n=2)$, infrastructure $(n=17)$, weather $(n=6)$, and terrain/distance $(n=12)$.

Poor weather $(n=17)$ was the most frequently cited battier that prevented the participants from choosing to $\mathrm{AC}$, followed closely by a lack of supportive infrastructure $(n=12)$. Infrastructure included the availability and maintenance of bike paths, sidewalks, crossing guards etc., especially as it pertained to traveling safely with their child. One participant explained, "a good network of bike paths is absolutely the number one important thing. And well-maintained bike paths." The importance of proper infrastructure is reinforced by it being the most frequently cited facilitator of $\mathrm{AC}(\mathrm{n}=17)$. The second most cited facilitator was the terrain/distance that the commute involved $(n=12)$.

Table 5. Illustrative quotes for environmental influences on active commuting

\begin{tabular}{|c|c|}
\hline Theme & Quote \\
\hline $\begin{array}{l}\text { Weather } \quad \text { and } \\
\text { associated logistics } \\
\text { (barrier) }\end{array}$ & $\begin{array}{l}\text { "The biggest barrier I would say is just the } \\
\text { logistics of it...it's a pain in the neck to wear the } \\
\text { appropriate clothes on the bike and then have to } \\
\text { change... where I am there's not easy access to } \\
\text { showers or changing rooms.. So it's a pain in the } \\
\text { neck. - Male, } 40\end{array}$ \\
\hline $\begin{array}{l}\text { Infrastructure } \\
\text { (barrier) }\end{array}$ & $\begin{array}{l}\text { "I wish there would be more covered bicycle } \\
\text { parking for when it rains later in the day. I want } \\
\text { my bike to be protected" - Female, } 36 \\
\text { "Things [at my worksite], mainly bike racks, the } \\
\text { more the better...I feel that more people are riding } \\
\text { their bikes which is good but it's true that I can't } \\
\text { find a place to park my bike so if [workplace] can } \\
\text { just continue to put in bike racks I think that } \\
\text { would be great." - Female, } 46\end{array}$ \\
\hline Weather (barrier) & $\begin{array}{l}\text { "I was willing to bike in colder or hotter weather, } \\
\text { and bike in the rain and maybe a little bit of } \\
\text { snow. But now with kids I'm more conservative. } \\
\text { I don't want them to be in danger so I won't } \\
\text { travel in really cold conditions or really slippery } \\
\text { conditions." - Female, } 36\end{array}$ \\
\hline $\begin{array}{l}\text { Terrain/Distance } \\
\text { (barrier) }\end{array}$ & $\begin{array}{l}\text { "The distance is a huge factor, and the terrain. } \\
\text { We lived in [neighborhood] before we moved } \\
\text { here. We did walk frequently there, but we never } \\
\text { biked because there were big hills." - Female, } 34\end{array}$ \\
\hline $\begin{array}{l}\text { Infrastructure } \\
\text { (facilitator) }\end{array}$ & $\begin{array}{l}\text { "One thing that is really critical for me is being } \\
\text { able to find a safe route. Safety is definitely } \\
\text { something that is on my radar in terms of being } \\
\text { able to bike with [my kids]." - Female, } 40 \\
\text { "I can take the bike path. It's very easy to } \\
\text { commute, I'm not on any major roads, it's easy" } \\
\text { - Female, } 46 \\
\text { "It helps the fact that there is a bike rack, there's } \\
\text { lots of bike racks at [worksite]... The [city } \\
\text { government] maintains bike paths and that does } \\
\text { make a difference" - Male, } 40\end{array}$ \\
\hline $\begin{array}{l}\text { Weather } \\
\text { (facilitator) }\end{array}$ & $\begin{array}{l}\text { "I bike to work everyday of the week in spring, } \\
\text { summer and fall... I'll bike if it's a nice day" - } \\
\text { Male, } 43\end{array}$ \\
\hline $\begin{array}{l}\text { Terrain/Distance } \\
\text { (facilitator) }\end{array}$ & $\begin{array}{l}\text { "I live close enough. Four and a half miles is an } \\
\text { easy commute... If I lived farther it would be } \\
\text { harder to do." - Male, } 43\end{array}$ \\
\hline
\end{tabular}

\section{Discussion}

In the United States, AC remains quite low, and efforts to reach groups that have relatively little participation need to be targeted to address the influences on this behavior. This study is among the first to examine how parents, a group with low AC, are able to successfully include active travel into their work day and provides insight on strategies to develop further interventions.

As noted in previous studies, enjoyment and habit strength $[23,32]$ were found to relate to $\mathrm{AC}$ in the current study. The illustrative quotes highlighted the value that many of the parents placed on their commute time; enjoying the time they spent traveling to work. With high rates of stress associated with balancing work and home life [33], regular PA can help buffer the negative health effects of stress and improve overall mental health. Active commuting provides a time saving, multi-tasking option for parents, traveling to work while also being physically active. A number of studies have indicated that those who actively travel to work are more likely to meet current PA recommendations, which is associated with a plethora of positive physical and mental health and chronic disease prevention benefits [34,35,36,37,38].

One of the most informative findings in the current study was the mention of accessories to help parents safely and easily travel with their children. There are a number of different option for parents to bike with their children including: bike trailers that are pulled behind the parent's bike, child seats installed on the parents' bike (e.g., behind the seat or in front of the handlebars), tagalongs (which have their own handlebars and allow the children to pedal), or tandem bicycles (multi-person bicycles) [39]. Although not as common in the United States, cargo bicycles are increasing in use in Europe $[40,41]$ and may provide parents with flexibility for transporting their children and other items (e.g., groceries, materials for work, etc.). In Copenhagen one quarter of families with more than two children own a cargo bicycle. As noted in the current study, safety concerns are paramount when transporting children via active modes [42] and for parents who are not as confident and comfortable with their own bicycling skills this may be a significant barrier. Previous research has noted that infrastructure that supports biking safety may be a more significant influence on women compared with men [43]. Further research should address whether this would also be relevant for parents actively traveling with their children.

Environment was one of the most consistent themes that affected the choice to AC. These results are consistent with the abundance of evidence that has noted weather as a strong determinant of AC participation [44,45,46]. Although weather is not something that can be controlled there are several things that can be implemented within a community to lessen the effect that weather has on the public. The maintenance of infrastructure is crucial to encourage $\mathrm{AC}$ in poor weather. Having safe bike paths that are properly maintained can allow people to bike or walk even if it is raining/snowing. Additionally, having covered bike parking stations will encourage AC even when the weather is poor because people will not be 
worried that their bikes (and trailers) will be damaged by the rain/snow.

Another recurring theme was that having support and being able to schedule efficiently with one's spouse was critical to allow for AC. Given the study population, this was a very important factor to examine in detail. As previously mentioned parents tend to have lower rates of AC than the general population, which is possibly due to the extra scheduling challenges and childcare arrangements. Spousal support and scheduling with spouse were the two most cited facilitators of interpersonal factors, reinforcing how important they are, in line with other studies about AC and physical activity and general $[17,25,47,48,49]$.

This study yielded a number of relevant insights for developing interventions to promote $\mathrm{AC}$ among parents. Skill building and confidence building could be targeted with programs to teach about appropriate route planning, selecting the proper equipment and conducting practice runs without the children so parents could better gage time and effort required. A peer mentor program could also be effective for parents, having a successful active commuting parent to provide guidance and encouragement could provide the necessary social support to adopt the behavior. Additionally, a spousal support initiative could be a viable strategy, providing a spouse with educational materials on the benefits of AC and the notable physical and mental health benefits so they would be more likely to encourage and support AC participation for their spouse. Lastly, at a community or workplace level, providing adequate infrastructure and support for walkers and bikers to enhance safety and convenience would not only increase the likelihood of $\mathrm{AC}$ for parents but for all community members.

Although this study yielded a number of important insights into parental AC participation, there were a number of limitations. This study was limited due to its relatively small sample size $(n=19)$ and lack of diversity. All participants were Caucasian and lived in the same general area where they had access to the same types of routes and infrastructure and all participants self-reported their current health to be good $(n=4)$, very good (11), and excellent $(n=3)$. Some recommendations for future studies are to increase the sample size and diversity of the sample population. It would also be worthwhile to examine how the rate of $\mathrm{AC}$ amongst parents differs in similar sized communities throughout the United States where weather might be always warm or always cold, and parents might be better adapted to the consistency of weather.

\section{Conclusion}

This study illustrates the need for future research to help find strategies to increase the rate of parents AC. Our findings show that even among individuals who have been successful active commuters there are a number of challenges that remain. This study identified a number of things that can be implemented at the institutional and community level that can help encourage the public and parents specifically to AC. A number of individual and social factors can be targeted for intervention to increase AC participation among parents. Future studies should build upon the key factors highlighted in this study to help develop solutions to the lack of AC participation in the population.

\section{References}

[1] Physical Activity Guidelines Advisory Committee. Physical Activity Guidelines Advisory Committee Report, 2008. In. Washington DC: US Department of Health and Human Services; 2008.

[2] United States Department of Health and Human Services. Physical Activity Guidelines for Americans. In; 2008.

[3] Brownson R.C., Boehmer T.K.andLuke D.A. "Declining rates of physical activity in the United States: what are the contributors?", Annu Rev Public Health, 26: 421-43, 2005.

[4] Caspersen C.J., Pereira M.A.andCurran K.M. "Changes in physical activity patterns in the United States, by sex and crosssectional age", Med Sci Sports Exerc, 32(9): 1601-9., 2000.

[5] Trost S.G., Pate R.R., Sallis J.F., Freedson P.S., Taylor W.C., Dowda M.andSirard J. "Age and gender differences in objectively measured physical activity in youth", Medicine and science in sports and exercise, 34(2): 350-355, 2002.

[6] Hull E.E., Rofey D.L., Robertson R.J., Nagle E.F., Otto A.D.andAaron D.J. "Influence of marriage and parenthood on physical activity: a 2-year prospective analysis", Journal of physical activity \& health, 7(5): 577, 2010

[7] Brown W.J.andTrost S.G. "Life transitions and changing physical activity patterns in young women", American Journal of Preventive Medicine, 25(2): 140-143, 2003.

[8] Brown W.J., Heesch K.C.andMiller Y.D. "Life events and changing physical activity patterns in women at different life stages", Annals of Behavioral Medicine, 37(3): 294-305, 2009.

[9] Engberg E., Alen M., Kukkonen-Harjula K., Peltonen J.E., Tikkanen H.O.andPekkarinen H. "Life events and change in leisure time physical activity: a systematic review", Sports Med, 42(5): 433-47, 2012

[10] Hamer M.andChida Y. "Active commuting and cardiovascular risk: a meta-analytic review", Prev Med, 46(1): 9-13, 2008

[11] Xu H., Wen L.M.andRissel C. "The relationships between active transport to work or school and cardiovascular health or body weight a systematic review", Asia-Pacific journal of public health, 25(4): 298-315, 2013

[12] Grasser G., Van Dyck D., Titze S.andStronegger W. "Objectively measured walkability and active transport and weight-related outcomes in adults: a systematic review", International journal of public health, 58(4): 615-625, 2013.

[13] Humphreys D.K., Goodman A.andOgilvie D. "Associations between active commuting and physical and mental wellbeing", Preventive medicine, 57(2): 135-139, 2013.

[14] Bopp M., Bopp C.andSchuchert M. "Active Transportation to and on Campus is Associated With Objectively Measured Fitness Outcomes Among College Students", Journal of physical activity \& health, 12(3): 418-423, 2015.

[15] McKenzie B. "Modes less traveled-bicycling and walking to work in the United States: 2008-2012", US Census Bureau, New York, 2014.

[16] Bopp M., Kaczynski A.T.andCampbell M.E. "Social Ecological Influences on Work-Related Active Commuting Among Adults", Am J Health Behav, 37(4): 543-554, 2013.

[17] Panter J.R., Jones A.P., van Sluijs E.M., Griffin S.J.andWareham N.J. "Environmental and psychological correlates of older adult's active commuting", Med Sci Sports Exerc, 43(7): 1235-43, 2011.

[18] Pucher J., Buehler R., Merom D. and Bauman A. "Walking and cycling in the United States, 2001-2009: evidence from the National Household Travel Surveys", Am J Public Health, 101 Suppl 1: S310-7, 2011.

[19] Whitfield G.P., Paul P.andWendel A.M. "Active transportation surveillance-United States, 1999-2012”, MMWR: Surveillance summaries, 64(Suppl 7): 1-17, 2015.

[20] McLeroy K.R., Bibeau D., Steckler A.andGlanz K. “An ecological perspective on health promotion programs", Health Education Quarterly, 15(4): 351-377, 1988

[21] Panter J., Griffin S., Dalton A.M.andOgilvie D. "Patterns and predictors of changes in active commuting over 12 months", Prev Med, 57(6): 776-84, 2013 
[22] Panter J.R.andJones A. "Attitudes and the environment as determinants of active travel in adults: what do and don't we know?", J Phys Act Health, 7(4): 551-61, 2010.

[23] de Bruijn G.J.andGardner B. "Active commuting and habit strength: an interactive and discriminant analyses approach", $\mathrm{Am} \mathrm{J}$ Health Promot, 25(3): e27-36, 2011.

[24] de Bruijn G.J., Kremers S.P., Singh A., van den Putte B.andvan Mechelen W. "Adult active transportation: adding habit strength to the theory of planned behavior", Am J Prev Med, 36(3): 189-94, 2009.

[25] Campbell M.E.andBopp M. "An Examination of the Relationship of Interpersonal Influences With Walking and Biking to Work", $J$ Public Health Manag Pract, 19(6): 521-4, 2013.

[26] Kaczynski A.T., Bopp M.J.andWittman P. "Association of workplace supports with active commuting", Prev Chronic Dis, 7(6): A127, 2010.

[27] Panter J., Heinen E., Mackett R.andOgilvie D. "Impact of New Transport Infrastructure on Walking, Cycling, and Physical Activity", Am J Prev Med, 50(2): e45-53, 2016.

[28] Dalton A.M., Jones A.P., Panter J.R.andOgilvie D. "Neighbourhood, Route and Workplace-Related Environmental Characteristics Predict Adults' Mode of Travel to Work", PLoS One, 8(6): e67575, 2013.

[29] Yang L., Hipp J.A., Adlakha D., Marx C.M., Tabak R.G.andBrownson R.C. "Choice of commuting mode among employees: Do home neighborhood environment, worksite neighborhood environment, and worksite policy and supports matter?", J Transp Health, 2(2): 212-218, 2015.

[30] McCormack G.R.andShiell A. "In search of causality: a systematic review of the relationship between the built environment and physical activity among adults", Int J Behav Nutr Phys Act, 8: 125, 2011.

[31] The Council of Economic Advisors. Nine facts about American families and work; 2014

[32] Páez A.andWhalen K. "Enjoyment of commute: a comparison of different transportation modes", Transportation Research Part A: Policy and Practice, 44(7): 537-549, 2010.

[33] United States Department of Labor. Chapter 3: Work and Fmaily.

[34] Norwood P., Eberth B., Farrar S., Anable J.andLudbrook A "Active travel intervention and physical activity behaviour: An evaluation", Social Science \& Medicine, 113: 50-58, 2014.

[35] Shephard R.J. "Is active commuting the answer to population health?", Sports Med, 38(9): 751-8, 2008
[36] Gordon-Larsen P., Nelson M.C.andBeam K. “Associations among active transportation, physical activity, and weight status in young adults", Obes Res, 13(5): 868-75, 2005.

[37] Brockman R.andFox K.R. "Physical activity by stealth? The potential health benefits of a workplace transport plan", Public Health, 125(4): 210-6, 2011

[38] Bopp M., Kaczynski A.T.andCampbell M.E. "Health-related factors associated with mode of travel to work", J Environ Public Health, 2013: 242383, 2013

[39] Bike Portland. Riding with kids: Which bike set-ups work best? In; 2008.

[40] Barner E. It's boom time for Cargo Bikes. In; 2014.

[41] Maus J. Summit starts with lessons from Copenhagen. In; 2009.

[42] healthychildren.org. Baby on board: Keeping safe on a bike. In; 2015

[43] Akar G., Fischer N.andNamgung M. "Bicycling choice and gender case study: The Ohio State University", International Journal of Sustainable Transportation, 7(5): 347-365, 2013.

[44] Flynn B.S., Dana G.S., Sears J.andAultman-Hall L. "Weather factor impacts on commuting to work by bicycle", Preventive medicine, 54(2): 122-124, 2012.

[45] Nankervis M. "The effect of weather and climate on bicycle commuting", Transportation Research Part A: Policy and Practice, 33(6): 417-431, 1999.

[46] Heinen E., Van Wee B.andMaat K. "Commuting by bicycle: an overview of the literature", Transport reviews, 30(1): 59-96, 2010.

[47] Eyler A.A., Brownson R.C., Donatelle R.J., King A.C., Brown D.andSallis J.F. "Physical activity social support and middle- and older-aged minority women: results from a US survey", Soc Sci Med, 49(6): 781-9, 1999.

[48] Bauman A.E., Reis R.S., Sallis J.F., Wells J.C., Loos R.J.andMartin B.W. "Correlates of physical activity: why are some people physically active and others not?", Lancet, 380(9838): 258-71, 2012.

[49] Marcus B.H., Williams D.M., Dubbert P.M., Sallis J.F., King A.C., Yancey A.K., Franklin B.A., Buchner D., Daniels S.R.andClaytor R.P. "Physical activity intervention studies: what we know and what we need to know: a scientific statement from the American Heart Association Council on Nutrition, Physical Activity, and Metabolism (Subcommittee on Physical Activity); Council on Cardiovascular Disease in the Young; and the Interdisciplinary Working Group on Quality of Care and Outcomes Research", Circulation, 114(24): 2739-52, 2006. 